\title{
MEMÓRIAS PÓSTUMAS DE UMA MORTE IMPOSSÍVEL: A PROSA DE QUEM NÃO PODE MAIS CONTAR
}

\section{CID OTTONI BYLAARDT}

Universidade Federal do Ceará

Fortaleza, Ceará, Brasil

Resumo: Brás Cubas, o defunto escritor de Machado de Assis, enuncia a prosa de quem não pode mais contar, encenando a impossibilidade de dizer, a qual, no pensamento de Maurice Blanchot, corresponde à impossibilidade da morte. Cubas morre, mas na realidade vive, estranha condição de quem em verdade não morreu porque não abandonou o mundo, mas vive a morrer porque eliminou a possibilidade de morrer após a morte. A astúcia de Cubas consiste em dar a impressão de fraqueza na vida e fora dela, fortalecendo-se na ressurreição da morte, na não negação de sua possibilidade. A literatura, assim, situa-se do outro lado da morte e da compreensão; ela pertence ao domínio da ausência de conclusão. Este texto, ao estabelecer um diálogo entre o romance de Machado e o pensamento de Blanchot, pretende mostrar como se realiza essa impossibilidade.

Palavras-chave: Brás Cubas; literatura; impossibilidade da morte

\section{POSTHUMOUS MEMORIES OF AN IMPOSSIBLE DEATH: PROSE BY ONE WHO CAN NO LONGER NARRATE}

Abstract: Brás Cubas, the dead writer excogitated by Machado de Assis, tells the tale of someone who can recount no more a story and thus stages the impossibility of saying, which according to Maurice Blanchot, is related to the impossibility of dying. Cubas dies, but he actually lives, which sets up the strange situation where he did not really die because he did not leave the world and yet lives to die because he has eliminated the possibility of dying after death. Cubas' cunning is in pretending he is weak both in and out of life, thus strengthening himself in his resurrection, in the nonnegation of its possibility. In this way literature stays opposite to death and understanding; it belongs to the realm of the inconclusive. By establishing a dialogue between Machado's novel and Blanchot's thinking, the aim of this article is to show how this impossibility is achieved.

Keywords: Brás Cubas; literature; the impossibility of death 
literatura se ergue da perda do fogo, do lugar, da oração. E ao
construir seu discurso funda seu próprio fogo, sua fórmula, seus
lugares, assim como Brás Cubas ergueu, após sua morte, um mundo em que a própria morte perdeu seu lugar. Essa história de perdas e ganhos da criação literária pode ser evocada por uma narrativa emblemática referida, a partir de Gershom Scholem, por Giorgio Agamben no livro Il fuoco e il racconto:

Quando Baal Schem, o fundador do chassidismo, devia resolver uma tarefa difícil, ia a um certo lugar no bosque, acendia um fogo, fazia as orações, e assim o que desejava se realizava. Quando, uma geração depois, Maggid di Meseritsch se encontrou diante do mesmo problema, ele se colocou no mesmo lugar do bosque e disse: "Não sabemos mais acender o fogo, mas podemos dizer as orações" - e tudo se resolveu conforme seu desejo. Ainda uma geração depois, Rabbi Mosche Leib di Sassov se encontrou na mesma situação, foi ao bosque e disse: "Não sabemos mais acender o fogo, não sabemos mais dizer as orações, mas conhecemos o lugar no bosque, e isto deve bastar". E de fato bastou. Mas quando uma outra geração transcorreu e Rabbi Israel di Rischin defrontou-se com a mesma dificuldade, permaneceu em seu castelo, deixou-se estar em sua cadeira dourada e disse: "Não sabemos mais acender o fogo, não somos capazes de dizer as orações, não conhecemos nem mesmo o lugar no bosque: mas de tudo isso podemos contar a história". E, mais uma vez, isso bastou. ${ }^{1}$

O pensador italiano diz que essa passagem pode ser lida como uma alegoria da literatura, e faz algumas reflexões sobre o texto literário, particularmente sobre o romance. Entre outros comentários, Agamben diz que o romance narra a própria perda do fogo, da oração e do lugar, erguendo seu reino da falta, da ausência.

Brás Cubas, o famigerado defunto escritor de Machado de Assis, aquele que já perdeu fogo, lugar e orações, que já se privou de tudo, e ao mesmo tempo ganhou o tudo do infinito, enuncia a prosa de quem não pode mais contar, encenando a impossibilidade de dizer, a qual, no pensamento de Maurice Blanchot, corresponde à impossibilidade da morte. $\mathrm{Na}$ fala ao leitor que antecede o relato, Brás Cubas diz que o livro é "obra de finado": 2 o que teve

\footnotetext{
${ }^{1}$ AGAMBEN, Il fuoco e il racconto, p. 7 . O texto em português foi traduzido pelo autor deste ensaio.

2 ASSIS, Memórias póstumas de Brás Cubas, p. 9.
} 
fim finou, o fim que permite compreender. Após o fim, abre-se o infinito, o que cai além da compreensão, ao perder o direito à morte. A literatura, assim, situa-se do outro lado da morte e da compreensão; ela pertence ao domínio em que "a conclusão se torna o desaparecimento de qualquer conclusão", 3 nas palavras de Blanchot. A obra em si mesma é tudo: é ela que fica, indiferente aos cem leitores de Stendhal, às opiniões dos graves e frívolos, e sobretudo às invectivas dos críticos, que procuram nela as explicações para o texto literário, com muitas perguntas e milhares de respostas, explicações que garantem o inexplicável.

O próprio Cubas faz várias perguntas e ensaia respostas, titubeando explicações sobre o livro e a literatura. Elas são diversas e contraditórias, às vezes hesitantes, assegurando a impossibilidade de fechar as conclusões, atestando sua recusa de dar um fim à literatura. Postado no fim dos tempos, sem ter mais direito à morte, o escritor defunto não consegue fazer vigorarem as respostas, atestando a impotência de afirmação do texto literário, assim como a sua impotência de negação, considerando o desvio que a literatura promove em relação à linguagem usual. No cotidiano, a linguagem nega seu referente, uma vez que não retém dele nada além de sua ausência, daquilo que ele não é. Assim como a morte é a potência do mundo finito, a negação é a potência da linguagem corrente, em que as coisas podem ser negadas e os seres podem morrer, transformados em palavra. $\mathrm{O}$ assassinato do objeto permite seu renascimento como ideia, como outra coisa, que possibilita aos humanos sua compreensão e o consequente desaparecimento também da palavra. Reter as palavras sem permitir que elas retornem ao referente é garantir sua saúde, para a eficácia da afirmação de nossas convicções. De forma diferente age a literatura. Cessadas as amarras que propiciam compreender, a palavra da literatura erra sem destino ou porto seguro. No incrível capítulo LXXI de Memórias póstumas de Brás Cubas, o narrador defunto desengana o leitor da possibilidade de trilhar caminhos na literatura, de apontar uma direção:

\section{CAPÍTULO LXXI}

\section{O senão do livro}

Começo a arrepender-me deste livro. Não que ele me canse; eu não tenho que fazer; e, realmente, expedir alguns magros capítulos para esse

\footnotetext{
${ }^{3}$ BLANCHOT, A parte do fogo, p. 330.
} 
mundo sempre é tarefa que distrai um pouco da eternidade. Mas o livro é enfadonho, cheira a sepulcro, traz certa contração cadavérica; vício grave, e aliás ínfimo, porque o maior defeito deste livro és tu, leitor. Tu tens pressa de envelhecer, e o livro anda devagar; tu amas a narração direita e nutrida, o estilo regular e fluente, e este livro e o meu estilo são como os ébrios, guinam à direita e à esquerda, andam e param, resmungam, urram, gargalham, ameaçam o céu, escorregam e caem...

E caem! - Folhas misérrimas do meu cipreste, heis de cair, como quaisquer outras belas e vistosas; e, se eu tivesse olhos, dar-vos-ia uma lágrima de saudade. Esta é a grande vantagem da morte, que, se não deixa boca para rir, também não deixa olhos para chorar... Heis de cair. ${ }^{4}$

Eis o estilo gago de Machado, duplamente depreciado por Sílvio Romero: tanto na pessoa do escritor, por ser "legítimo representante da subraça brasileira cruzada", 5 como em sua escrita, justamente por ser tatibitate, traço que acabou firmando-se possivelmente como a grande marca do estilo machadiano. O referido minicapítulo, que se coloca lá pelo meio da narrativa de Cubas, faculta uma reflexão sobre o texto literário e sua recepção. Postado na eternidade, o enunciador parece usar a literatura como uma forma de ligálo ao mundo dos humanos, mas sua condição de habitante do infinito propicialhe a criação de um produto franzino, obra magra que o que faz é desobrar, uma vez que não age, "que não edifica nem destrói", ${ }^{6}$ no dizer do próprio Brás, e essa inação, ou, como quis Blanchot, esse désoeuvrement, provoca o desagrado do leitor, na visão do escritor cadáver. O livro é enfadonho e cadavérico, vício que ele considera ao mesmo tempo grave e ínfimo, uma contradição. $\mathrm{O}$ oximoro parece andar de mãos dadas com a hesitação e a dificuldade de afirmar; e, consequentemente, de negar. Para o morador do undiscovered country de Hamlet, esse tipo de vício não é propriamente defeito, porque, uma vez que dispõe de todo o infinito, é impossível que algum método ali seja operante, justamente pela impossibilidade de se delimitar o discurso. Para o leitor, que vive sob as leis finitas, ele que tem "pressa de envelhecer", e consequentemente caminha para a morte, seu fim, sua conclusão, seu arremate, o livro carece de método, de uma loyauté méthodique que estabeleça o fim que permite compreender, e, antes do fim, a estrada que conduz ao fim, que, espera-se, seja "direita e nutrida", "regular e fluente". "Lição de cor e

\footnotetext{
${ }^{4}$ ASSIS, cit., p. 699.

${ }^{5}$ ROMERO, História da literatura brasileira, p. 1502.

${ }^{6}$ ASSIS, cit., p. 629.
} 
compostura na aula": ${ }^{7}$ é o que exigia de Brás Cubas seu velho mestre de primeiras letras - "nada mais, nada menos do que quer a vida, que é das últimas letras". ${ }^{8}$ É o que quer o leitor do romance que representa a vida: a lição de cor, a compostura metódica que confere sentido à narrativa. Do outro lado está o infinito, que só lhe concede a ebriedade, as guinadas errantes, os urros, as quedas... Assim, a conclusão, que, segundo Blanchot, é a ausência de conclusão, é que as folhas do livro vão cair, vítimas do desastre da incompreensão, do naufrágio da falta de sentido. E, afinal, como a morte não deixa boca para sorrir - e nem para dizer -, também não permite sofrimento nem lamentação. O que fica é uma escritura.

O ser que outrora fizera parte do mundo dos homens, numa sociedade masculina, teve suas frias carnes roídas pelos vermes, conforme dedicatória de Cubas ao primeiro da fila. O verme pertence ao mundo finito, bem como as frias carnes de um cadáver, aquele que terminou para concluir uma vida sem conclusões, mas cujo termo garante a continuação desta humanidade eternamente hipocondríaca e miserável, ainda que ele, o ser que precedeu o cadáver, não tenha transmitido a nenhuma criatura esse legado. A dedicatória é feita com "saudosa lembrança". Saudosa lembrança de quê? Do verme? Do cadáver que demarca o fim de uma vida? Possivelmente dos dois. Ou, ainda, de um terceiro: a própria vida cuja ausência é assinalada pela presença do cadáver e do verme que rói os despojos de vida, permitindo a Brás Cubas, homem e obra, penetrar no infinito.

Para Blanchot, além da errância que desliza em sua ambiguidade, a palavra literária padece da angústia e do delírio da origem. Sendo pouca para o tanto que deve comportar, parece querer compensar sua carência de excessos inacessíveis com a busca do momento anterior ao nome. Ocorre-nos a visão de Brás Cubas escanchado em seu onírico paquiderme a correr sua involuntária carreira em busca da origem dos tempos. Um sonho, sim, assim como é o sonho da literatura achar a palavra primeira, descontaminada, em sua origem de palavra. A carreira parece-lhe, a Cubas, uma viagem sem destino, ao que lhe retruca o hipopótamo:"- Engana-se, replicou o animal, nós vamos à origem dos séculos". ${ }^{9}$ A proposta é fascinante, uma vez que nosso poder é fazer o que é depois. Como buscar o que é antes? Como achar o que estava ali e não está mais, que se tornou indisponível? A tentativa de Brás no

${ }^{7}$ Idem, p. 643.

${ }^{8}$ Ibidem.

${ }^{9}$ Idem, p. 632. 
lombo do paquiderme parecia fascinante, em princípio, mas de sedutora passou a "enfadonha e extravagante, o frio incômodo, a condução violenta, e o resultado impalpável". ${ }^{10}$ Impalpável, como o relato de Brás Cubas, como a literatura, que, assim como os séculos, irrita-se "com lhe devassarem a origem" ${ }^{11} \mathrm{O}$ próprio autor, no início do capítulo VII, adverte que se trata do relato de um delírio; é, portanto, uma fabulação; consequentemente, é literatura, como tudo o que se encontra no livro, domínio onde "tudo escapava à compreensão do olhar humano", ${ }^{12}$ conforme afirma o delirante. Brás Cubas faz essa referência ao se deparar com uma imensa figura de mulher, que adiante se apresentou como Natureza ou Pandora. Ao deparar-se frente a frente com a estranha visagem, Brás Cubas é dominado pelo fascínio, e quem está fascinado não pode compreender. Assim, ele dá à pergunta "- Entendesteme?", formulada pelo fantasma, a seguinte resposta:

- Não, respondi; nem quero entender-te; tu és absurda, tu és uma fábula. Estou sonhando, decerto, ou, se é verdade que enlouqueci, tu não passas de uma concepção de alienado, isto é, uma coisa vã, que a razão ausente não pode reger ou palpar. ${ }^{13}$

Blanchot tenta compreender o que não pode ser compreendido, e arrisca aqui e ali em sua obra o que seria o ato de escrever:

"Escrever é fazer-se eco do que não pode parar de falar - e, por causa disto, para vir a ser o seu eco, devo de uma certa maneira impor-lhe silêncio." ${ }^{\prime 14}$

"Escrever é entregar-se ao fascínio da ausência de tempo."15

"Escrever é entrar na afirmação da solidão onde o fascínio ameaça."16

Quem está fascinado não pode compreender, porque o que vê não pertence ao mundo real, mas ao mundo intangível da fascinação. Sem poder atribuir sentido, concluir, finalizar, aquele que escreve só convive com o silêncio, a solidão, o interminável, o absoluto. Como diz a visão fascinante a

\footnotetext{
${ }^{10}$ Idem, p. 633.

${ }^{11}$ Ibidem.

12 Ibidem.

${ }^{13}$ Idem, p. 634.

14 BLANCHOT, O espaço literário, p. 17.

${ }^{15}$ Idem, p. 20.

${ }^{16}$ Idem, p. 24.
} 
Cubas: "Grande lascivo, espera-te a voluptuosidade do nada". ${ }^{17}$ Entretanto, o personagem quer viver, a nenhum de nós interessa como viventes aventurarse pelo país desconhecido, e assim ele suplica a Pandora que lhe dê mais alguns instantes de vida, mas depois muda de ideia, e a viagem vertiginosa continua, a ponto de escapar a qualquer compreensão.

Curiosamente, a Razão convida a Sandice a retirar-se no capítulo seguinte, para que se instaure a ordem, e afinal, em que pese toda a resistência da loucura, consegue expulsá-la - ainda que momentaneamente. A alternância entre razão e desrazão faz lembrar a reflexão de Blanchot sobre a mão que escreve (a mão "doente") e a mão que intervém (a mão do poder). A primeira obedece a uma ordem imperiosa, uma exigência inelutável, a que o pensador dá o nome de "preensão persecutória". ${ }^{18}$ A outra mão é a mão do domínio, a que procura garantir a compostura do escrito, e possivelmente sua intenção decorosa. Essa mão é a responsável pela expulsão da Sandice da casa do escritor, e também é ela quem declara a castidade do livro: "este livro é casto, ao menos na intenção; na intenção é castíssimo". ${ }^{19}$ Intenção e Razão andam de mãos dadas, ou compõem uma única mão, e é ainda essa mão que garante a resistência do autor a se entregar ao reino da fascinação, como um Ulisses a querer ouvir o canto das sereias sem ser arrebatado por elas, amarrando-se ao mastro. No capítulo "O recluso", o escritor repreende sua pena pela desordem que instaura no relato:

Pena de maus costumes, ata uma gravata ao estilo, veste-lhe um colete menos sórdido; e depois, sim, depois vem comigo, entra nessa casa, estira-te nessa rede que me embalou a melhor parte dos anos que decorreram desde o inventário de meu pai até $1842 .^{20}$

Esses são, segundo a concepção irônica de Blanchot, os "mais literários de todos os escritores", ${ }^{21}$ isto é, aqueles que parecem querer evitar os extremos da literatura, entregando-se à ação, à comunidade do trabalho, ao ofício de escrever e ao prazer de ser lido, e usufruir dessa glória.

A glória também está ao lado da intenção e da razão. Brás Cubas, no momento em que escreve, está imune à glória, coisa dos humanos, mas nem

\footnotetext{
${ }^{17}$ ASSIS, cit., p. 634.

18 BLANCHOT, O espaço literário, p. 15.

${ }^{19}$ ASSIS, cit., p. 645.

${ }^{20}$ Idem, p. 677.

${ }^{21}$ BLANCHOT, O espaço literário, p. 20.
} 
sempre foi assim. As opiniões sobre a importância da glória se polarizavam nos discursos do tio militar e do tio cônego. Para este, o amor da glória era a "perdição das almas", ${ }^{22}$ enquanto para aquele "o amor da glória era a coisa mais verdadeiramente humana que há no homem". ${ }^{23}$ Que o leitor decidisse sobre quem estaria certo, pois ele, Cubas, já havia decidido pela fama e pelo esplendor ao idealizar o emplasto, já perto do fim. Ainda quando jovem, a caminho de Coimbra, enquanto conjecturava sobre seu "grande futuro", ele aventava a hipótese de ser literato, embora não escrevesse nada. Após a morte do pai, o narrador declara que, entre outras atividades, "Escrevia política e fazia literatura", ${ }^{24}$ e acrescenta: "Mandava artigos e versos para as folhas públicas, e cheguei a alcançar certa reputação de polemista e poeta". ${ }^{25}$ Assim, o rapaz de futuro promissor não chegou à glória literária, o que seria o máximo, mas granjeou certa reputação, o que é mais importante do que o texto literário em si. Todos querem ser reconhecidos e elogiados pelo fazer literário, como o capitão do navio que levou Cubas a Portugal, o que temia que seus sentimentos atrapalhassem a perfeição dos versos; como também o primo de Virgília, o Luís Dutra, que "privava com as musas", segundo o enunciador, e ficava inquieto por lhes obter a aprovação para seus versos.

Que caminho é esse que o relato de Cubas segue? Afinal, ele pende para o trajeto da mão doente ou para a exigência profunda que não permite atrelamento ao mastro? Muitos foram os caminhos desenhados por leitores e críticos na trajetória desse texto fabuloso. Para Capistrano de Abreu, "O que é fundamental e orgânico é a descrição dos costumes, a filosofia social que está implícita". ${ }^{26}$ Segundo Schwarz, o romance da periferia do capitalismo "deixa entrever as grandes linhas de uma estrutura social", não apenas "como regra de composição da narrativa", mas também "como estilização de uma conduta própria à classe dominante brasileira". ${ }^{27}$ Regina Zilberman diz, sobre Cubas, que "sua biografia corresponde a uma interpretação da história nacional". ${ }^{28}$ Consoante Merquior, "não convém levar tão a sério esse ar sobrenatural, pois o fantástico não passa de um estratagema humorístico, de uma primeira manifestação de sarcasmo de Machado". ${ }^{29}$ Desfilam aos nossos olhos de pesquisador as leituras formalizantes, sociológicas, biográficas, existenciais,

\footnotetext{
${ }^{22}$ ASSIS, cit., p. 677.

${ }^{23}$ Idem, p. 628.

${ }^{24}$ Idem, p. 677.

${ }^{25}$ Idem, p. 643.

${ }^{26}$ ABREU, Capistrano de. Sobre as Memórias póstumas de Brás Cubas, p. 11.

${ }^{27}$ SCHWARZ, Um mestre na periferia do capitalismo: Machado de Assis, p. 14.

${ }^{28}$ ZILBERMAN, Memórias póstumas de Brás Cubas: à procura da história, p. 71.

${ }^{29}$ MERQUIOR, Gênero e estilo das Memórias póstumas de Brás Cubas, p. 140.
} 
morais... A maioria delas revela-se tão engenhosa quanto a ideia do emplasto, que teve a desvantagem de matar seu autor, o que os engenhos dos críticos não puderam fazer com a obra. Afinal, a literatura é para ser levada assim tão a sério?

Em A literatura e o direito à morte, Blanchot afirma que quando o que ele chama "réflexion imposante" - e que podemos entender como o discurso sério sobre a literatura - se aproxima do texto literário, "esta se torna uma força cáustica, capaz de destruir o que nela e na reflexão se poderia impor". ${ }^{30}$ Quando a crítica se afasta, então o romance e o poema voltam a ser eles mesmos, em sua essência. Essa imposição dos discursos críticos não escapa a Agamben, que, em um pequeno texto chamado "Defesa de Kafka contra seus intérpretes", afirma:

Sobre o inexplicável correm as mais diversas lendas. A mais engenhosa encontrada pelos atuais guardiões do templo ao remexerem nas velhas tradições - explica que, sendo inexplicável, ele permanece como tal em todas as explicações que dele foram dadas e continuarão a sê-lo nos séculos vindouros. São precisamente essas explicações que constituem a melhor garantia de sua inexplicabilidade. O único conteúdo do inexplicável - e nisso está a sutileza da doutrina - consistiria na ordem (verdadeiramente inexplicável): "- Explica!". Não podemos subtrair-nos a essa ordem, porque ela não pressupõe nada de explicável, ela própria é seu único pressuposto. Seja o que for que se responda ou não responda a essa ordem - mesmo o silêncio - será de qualquer modo significativo, conterá de qualquer modo uma explicação. ${ }^{31}$

Que rumo tomar? Optamos por vislumbrar o caminho do Cubas escritor para si mesmo, para o ponto em que ele que não tem mais direito à morte, não pode mais falar a palavra dos homens, que falam pelos deuses, que defendem os oprimidos etc., e esse ponto é feito de linguagem. Maurice Blanchot faz em um parágrafo uma interessante revisão da história da literatura:

A obra que foi palavra dos deuses, palavra da ausência dos deuses, que foi palavra exata, equilibrada, do homem, depois palavra dos homens em sua diversidade, em seguida palavra dos homens deserdados, daqueles que não têm a palavra, logo palavra do que não fala no homem, do segredo, do desespero ou do êxtase que se falta dizer, o que é que sempre foi subtraído de sua linguagem? Ela mesma. Quando tudo foi dito, quando o

\footnotetext{
30 BLANCHOT, A parte do fogo, p. 297.

${ }^{31}$ AGAMBEN, Ideia da prosa, p. 134.
} 
mundo se impõe como a verdade do todo, quando a história quer cumprir-se na realização do discurso, quando a obra nada mais tem a dizer e desaparece, é então que ela tende a tornar-se palavra da obra. $\mathrm{Na}$ obra desaparecida, a obra quereria falar, e a experiência converte-se na busca da essência da obra, a afirmação da arte, a preocupação da origem. $^{32}$

Quando tudo foi dito, o poder de dizer está perdido. Quando o fogo, a fórmula e o lugar se perderam, de tudo isso podemos contar a história. Se a literatura precisa de um conteúdo, se ela pretende convencer, ou denunciar, ou condenar, ou disciplinar, sua linguagem se coloca a serviço da transparência, do poder de dizer. Uma reflexão saborosa sobre a literatura e o poder está no capítulo LXXII de Memórias póstumas, "O bibliômano". Após ter discorrido sobre "O senão do livro", o escritor parece arrepender-se e ameaça suprimir o capítulo em que denuncia a imperfeição do romance e acusa o leitor por suas exigências de ordem. Imagina então um futuro leitor, setenta anos à sua frente, procurando pelo despropósito do livro, denunciado pelo autor no capítulo precedente. Ouçamos a voz de Brás Cubas:

Olhai: daqui a setenta anos, um sujeito magro, amarelo, grisalho, que não ama nenhuma outra coisa além dos livros, inclina-se sobre a página anterior, a ver se lhe descobre o despropósito; lê, relê, treslê, desengonça as palavras, saca uma sílaba, depois outra, mais outra, e as restantes, examina-as por dentro e por fora, por todos os lados, contra a luz, espaneja-as, esfrega-as no joelho, lava-as, e nada: não acha o despropósito. ${ }^{33}$

Observe-se que esse bibliômano do futuro tem nas mãos o único exemplar existente de Memórias póstumas de Brás Cubas, o que a torna uma obra duplamente singular. Se o bibliômano não lhe acha o despropósito, também não lhe decifra o propósito; afinal, aquilo é um romance, uma obra literária, sem força nem poder no mundo. E o mundo que se segue janela afora lhe aponta a direção do poder: "Nesse momento passa-lhe por baixo da janela um César ou um Cromwell, a caminho do poder". ${ }^{34}$

O narrador faz com que o bibliômano feche a janela, e a literatura aponta para outra direção. No movimento dos fins para o infinito, sua linguagem é

\footnotetext{
32 BLANCHOT, A parte do fogo, p. 233.

${ }^{33}$ ASSIS, cit., p. 698.

${ }^{34}$ Idem, p. 699.
} 
opaca, e o que ressai é seu poder de brilho. Esse movimento em direção à morte, que é morte na literatura, que é a impossibilidade da morte, que é estar a morrer sem fim, é um movimento contraditório, porém não dialético, na acepção que a metafísica ocidental nos ensinou, uma vez que não há aí resolução, síntese, conciliação. A existência de Brás Cubas se abre para o mundo, fazendo da morte uma tarefa sem fim em seus domínios.

Nesse espaço nada pode ser dito com autenticidade, não há verdade exemplar, as palavras traem a tolice do mundo e a impossibilidade de dizer, por mais que tolice e impossibilidade estejam investidas de uma linguagem nobre, à altura das melhores tradições das letras. Machado é cruel com a matéria que compõe o romance, e não economiza vulgaridades. Aqui descreve os trejeitos de cabeleireiro com que Brás enlaça e ajeita os cabelos de Virgília em um pente com diamantes, ali filosofa sobre a função dos calos, que aperfeiçoam a felicidade terrestre, mais adiante brinda o leitor com uma reflexão sobre a relação entre a competição dos chapeleiros, o nariz e o amor, logo mais imortaliza as pernas em um capítulo dedicado a elas, de outra feita procede a uma lucubração entre o número treze que o livrara de ir mofar em uma província do Norte e a égua de ruiva crina que substituíra as virgens ruivas de Tebas no sacrifício de Pelópidas... Sem contar o inusitado jumento em que Cubas vinha montado e que empacou, propiciando o episódio do almocreve.

Pode-se, assim, pensar em dois tipos de morte que se tensionam no texto literário: a primeira é autêntica, séria, garante a existência dos seres, permite a compreensão, possibilita a consecução das tarefas; a segunda é fugidia, montada num hipopótamo, inacessível como o fim e como a origem dos tempos.

A morte de Brás Cubas é o supremo instante em que o personagem se torna liberto da ordem do tempo. Este é o momento em que o tempo é eliminado pelo próprio tempo. O que está fora do tempo, portanto, disponibiliza para Cubas o tempo puro. A narrativa do defunto autor começa com o fim que, somente ele, permite que se compreenda o mundo e, do outro lado, permite que o escritor o transforme no mais terrível e mais belo dos mundos possíveis. O ponto fabuloso do encontro com a morte é que torna possível a Brás Cubas recompor o mundo no romance, no reino do ficcional.

A morte de Cubas acaba se transformando, assim, na impossibilidade da morte. Brás Cubas morre, mas na realidade vive; é uma condição estranha, ele em verdade não morreu, porque não abandonou o mundo nem a morte, então ele vive a morrer, porque eliminou a possibilidade de morrer após a morte. 
A astúcia de Cubas consiste em dar a impressão de fraqueza na vida e na morte, fortalecendo-se na ressurreição da morte, na não negação de sua possibilidade. Não houve em seu passamento nada de trágico, nada de fabuloso, apenas uma aparente passagem de um estado de ser a outro ser, "pausado e trôpego, como quem se retira tarde do espetáculo". ${ }^{35}$ Fabulosa, entretanto, é a possibilidade que essa passagem produz, de recriar o espetáculo do qual ele se torna, o personagem-narrador, seu senhor absoluto.

A causa mortis foi uma pneumonia; na realidade, segundo Brás Cubas, foi uma grande ideia que tomou conta de suas faculdades e impediu que o corpo se protegesse de uma corrente de ar. Enquanto ele esperava que, com a execução da ideia do emplasto, se notabilizasse entre os humanos, enquanto se via "ascender do chão das turbas, e remontar ao céu, como uma águia imortal", ${ }^{36}$ ele acabou encontrando o caminho da eternidade pela via de uma pneumonia. A fragilidade do corpo não foi capaz de esperar que a mente poderosa do homem pudesse engendrar a panaceia dos males do mundo.

O que é que torna fascinante esse romance? Qual teria sido a causa de sua canonização? Certamente não o conteúdo, que não poderia ser mais anódino, mais pleno da tolice que se encontra em qualquer esquina do mundo. A forma, possivelmente, também não, ele que, como representante do romance do século XIX, não procede de maneira digna e comportada para os padrões da época. Já nas primeiras notícias da publicação do livro, em 1881, Capistrano de Abreu perguntava: "As Memórias póstumas de Brás Cubas são um romance?". ${ }^{37}$ As memórias de Brás não conseguem comportar-se com o mínimo decoro em relação às leis de inventio, dispositio e elocutio. Sua moral é duvidosa, por mais que se tente atrelá-la a um momento histórico ou a um evento de classe. Maurice Blanchot reescreve Mallarmé afirmando que um poema não é a matéria de que é feito:

A obra faz aparecer o que desaparece no objeto. A estátua glorifica o mármore, o quadro não é feito a partir da tela e com ingredientes materiais, é a presença desta matéria que, sem ele, permaneceria escondida de nós. $\mathrm{E}$ o poema não é feito nem com ideias nem com palavras, mas é aquilo a partir do qual as palavras tornam-se sua aparência e a profundidade elementar sobre a qual essa aparência se abre e, entretanto, se fecha de novo. ${ }^{38}$

\footnotetext{
${ }^{35}$ Idem, p. 626.

${ }^{36}$ Idem, p. 630.

${ }^{37}$ ABREU, cit., p. 11.

${ }^{38}$ BLANCHOT, A parte do fogo, p. 224.
} 
Se o escritor se serve da palavra, e se o advogado também se serve da palavra, aquele a utiliza de maneira que ela não é propriamente utilizada, no sentido de se tornar útil, diferentemente do advogado, cujo uso tem a finalidade de provocar um resultado. Da mesma forma, a utilização artística da palavra não a nega, não a consome pelo uso, como ocorre com o discurso das leis, por exemplo. A palavra artística é afirmada em sua transformação em arte, é revelada em sua obscuridade, seguindo um caminho que só conduz a ela própria; isto é, o que fica na obra não são as palavras, mas aquilo em que as palavras se tornam, possivelmente seu mistério e sua indisponibilidade. Lembrando a narrativa de Gershom Scholem, podemos dizer que Memórias póstumas de Brás Cubas não sabe fazer fogo, não sabe orar, e abandonou seu lugar no bosque, mas de tudo isso pode contar a história, ainda que seja a história da ausência, a memória da perda do fogo, da fórmula, do lugar. O conteúdo e a forma são palpáveis, a obra é intangível.

Ainda que os preceitos da metodologia acadêmica condenem o ato, é irresistível terminar com uma citação de Antonio Candido, talvez a melhor parte de seu "Esquema de Machado de Assis": "O melhor que posso fazer é aconselhar a cada um que esqueça o que eu disse, compendiando os críticos, e abra diretamente os livros de Machado de Assis". ${ }^{39}$ Ouçamos o conselho do velho mestre.

Agradecimento: ao CNPq, que financiou a escritura deste artigo.

\section{Referências}

ABREU, Capistrano de. Sobre as Memórias póstumas de Brás Cubas. In: ASSIS, Machado de. Obra completa em quatro volumes. Vol. 1. Rio de Janeiro: Nova Aguilar, 2008.

AGAMBEN, Giorgio. Il fuoco e il racconto. Roma: Edizioni Notttempo, 2014. . Ideia da prosa. Tradução de João Barrento. Belo Horizonte: Autêntica Editora, 2012.

ASSIS, Machado de. Obra completa em quatro volumes. Vol. 1. Rio de Janeiro: Nova Aguilar, 2008.

BLANCHOT, Maurice. O espaço literário. Rio de janeiro: Rocco, 1987.

${ }^{39}$ CANDIDO, Esquema de Machado de Assis, p. 124. 
A parte do fogo. Rio de Janeiro: Rocco, 1997.

CANDIDO, Antonio. Esquema de Machado de Assis. In: ASSIS, Machado de. Obra completa em quatro volumes. Vol. 1. Rio de Janeiro: Nova Aguilar, 2008; também em: Vários escritos. 3 ed. rev. e ampl. São Paulo: Duas Cidades, 1995; 5 ed. Rio de Janeiro: Ouro sobre Azul, 2011.

MERQUIOR, José Guilherme. Gênero e estilo das Memórias póstumas de Brás Cubas. In: ASSIS, Machado de. Obra completa em quatro volumes. Vol. 1. Rio de Janeiro: Nova Aguilar, 2008; também em: Revista Colóquio/Letras. Ensaio, n. 8, p. 12-20, jul. 1972.

ROMERO, Sílvio. História da literatura brasileira. 7 ed. Vol. 5. Rio de Janeiro: José Olympio, 1980.

SCHWARZ, Roberto. Um mestre na periferia do capitalismo: Machado de Assis. São Paulo: Duas Cidades; Editora 34, 2000.

ZILBERMAN, Regina. Memórias póstumas de Brás Cubas: à procura da história. In: Crônicas da antiga corte: Literatura e memória em Machado de Assis. Belo Horizonte: Ed. UFMG, 2008.

CID OTTONI BYLAARDT é professor associado II do Departamento de Literatura e do Programa de Pós-Graduação em Letras da Universidade Federal do Ceará. E-mail: cidobyl@pq.cnpq.br. 